\title{
The Morphology and Position of the Pterion in a sample of Sri Lankan Adult Population
}

Nawarathna NGS ${ }^{1}$, Dissanayake DMMLB ${ }^{1}$, Sampath $\mathrm{PH}^{1}$, Manawarathna MRK ${ }^{1}$, Dissanayake $\mathrm{JK}^{2}$, Peiris $\mathrm{HRD}^{1}$, Nanayakkara $\mathrm{CD}^{1}$

'Division of Anatomy, Department of Basic Sciences, Faculty of Dental Sciences, University of Peradeniya.

${ }^{2}$ Department of Anatomy, Faculty of Medical Sciences, University of Peradeniya. *gayaninawa94@gmail.com

The pterion, defined as a $\mathrm{H}$-shaped sutural confluence formed by the frontal, parietal, temporal and sphenoid bones on the lateral surface of the skull overlies both the anterior branch of the middle meningeal artery and the lateral cerebral fissure. The present study was conducted to determine the morphology of the pterion, and its precise position with reference to surrounding anatomical landmarks in an adult Sri Lankan population. Sixty pteria of thirty skulls of known sex in an adult Sri Lankan population were investigated. The sutural pattern of the pterion on both left and right sides of each skull were recorded based on Murphy's classification. Linear distances were measured using a digital vernier caliper to the nearest $0.01 \mathrm{~mm}$. The predominant type of pterion observed in male and female combined sample was sphenoparietal (82.4\%), followed by stellate $(9.8 \%)$, and frontotemporal (3.9\%), and epipteric types $(3.9 \%)$. The mean distances from the center of the pterion to the frontozygomatic suture were $31.11 \pm$ $5.02 \mathrm{~mm}$ and $26.98 \pm 3.45 \mathrm{~mm}$; to the zygomatic arch, $38.92 \pm 3.55 \mathrm{~mm}$ and $36.16 \pm 3.83 \mathrm{~mm}$; to the mastoid process, $81.54 \pm 4.62 \mathrm{~mm}$ and $77.79 \pm$ $3.88 \mathrm{~mm}$; and to the external acoustic meatus, $53.62 \pm 2.58 \mathrm{~mm}$ and $51.91 \pm$ $2.98 \mathrm{~mm}$, in males and females, respectively. All the differences were statistically significant at the level of $p<0.05$. The pterion in the males was positioned at a higher point from the zygomatic arch than in females. The present study has shown that the sphenoparietal type of pterion predominates in this sample. 